\title{
The Importance of Public Awareness in Environmental Protection: A Case Study in Paktika, Afghanistan
}

\author{
Hizbullah Rahmani*†, Wafaurahman Wafa** and Fayaz Gul Mazloum Yar*** \\ *Department of Biology, Higher Education Institute of Paktika, Afghanistan \\ ** Department of Environmental Science, Kabul University, Afghanistan \\ ***Department of Geography, Nangarhar University, Afghanistan \\ $†$ Corresponding author: Hizbullah Rahmani; hezbullah.rahmani@gmail.com
}

Nat. Env. \& Poll. Tech.

Website: www.neptjournal.com

Received: 03-03-2021

Revised: 21-04-2021

Accepted: 01-05-2021

Key Words:

Environmental problems

Public awareness

Environmental protection

Environmental activities

\begin{abstract}
Public awareness and knowledge of environmental protection are crucial to avoid environmental pollutions. Lack of relevant scientific principles and lack of public awareness of environmental or other projects are hindrances to controlling environmental pollution. The objective of the study was to identify the importance of public awareness in environmental pollution management. Environmental education and public awareness are crucial to avoid environmental pollutions. The study aims to analyze public awareness of environmental protection. The study was conducted in Sharana, the center of Paktika province, and was attended by 71 students from the Paktika Higher Education Institute's Education Faculty. Questionnaires and field observations have been selected as methodologies for this research. The results of the study show that 59.2 percent of survey participants consider public awareness and 35.2 percent think that enforcement of environmental laws is important. People in Paktika do not take part in environmental activities due to a lack of public awareness and throw away pollutants everywhere. If this situation continues, it is not far off that it will turn into a disaster.
\end{abstract}

\section{INTRODUCTION}

Science's longevity as a discipline is closely connected to the effectiveness of its practice in society's daily lives. Lack of relevant scientific principles and lack of public awareness of environmental or other projects are hindrances to controlling environmental pollution (Ekmekçi \& Günay 1997). Public awareness of environmental protection is the ability to be aware of the changes that take place in the environment, including the world around us, the relationship between human behavior, and the quality of the environment. Human activities can have a significant impact on the terrestrial environment. Lack of adequate environmental knowledge is an obstacle in achieving a sustainable future for humankind at both global and local levels (Sola 2014).

The main requirement for high-school graduates is to assimilate not only special environmental awareness, but to enhance, enrich, systematize, and use it under various conditions (Nazarenko \& Kolesnik 2018). Curdt-Christiansen, (2020) stated that environmental education is very important in schools even at the start of school for children. Education is one of the major tools for raising public awareness, particularly in developing countries (Debrah et al. 2021).
A key concern for the future of mankind is public understanding of the climate. For reflecting national culture, it is one of the most important indicators. It represents many aspects of environmental situations, such as the awareness, actions, and attitude of people towards a sustainable society (Apichatibutarapong 2018). According to Apichatibutarapong (2018), environmental protection is any activity that maintains the quality of the environment at the individual, administrative or state level for the benefit of both the natural environment and human beings. Protecting the environment is a priority for future generations. Public awareness also gives us a sense of responsibility to keep natural resources for future generations. Environmental problems such as wastewater and waste management (Mukhtar et al. 2016) are among the world's most serious problems. Therefore, public awareness and participation are essential for effective organization and protection of the environment. The United Nations Convention on Climate Change and the Kyoto Protocol can only be achieved through the active participation of the public and key stakeholders. As governments are directly responsible for the reduction in greenhouse gas emissions, they should encourage businesses, communities, and individuals to change their behavior to comply with gas emissions restrictions. Therefore, public awareness and access to information are critical to supporting government policies and laws (UNEP 2006). 
Many environmental problems are caused not only by industrial and agricultural pollutants but also by a lack of public awareness. Furthermore, unplanned urbanization is causing some significant long-term implications on humans and the environment; water contamination caused by urban mess and air pollution due to traffic smoke is an emerging and extensive issue (Wafa et al. 2020). Therefore, raising public awareness about environmental protection is very important and necessary (Xua et al. 2011). Climate change can have short-term and long-term adverse effects on health. The number of deaths caused by climate change will rise by 250,000 each year between 2030 and 2050. The participation of the public, in addition to governments, international agencies, and non-governmental organizations, is essential to preventing such environmental problems. Such environmental problems can be easily controlled through public awareness, cooperation, and commitment (Rapaport \& Ashkenazi 2016).

Environmental protection education is one of the most important and fundamental goals of UNESCO-UNEP (1978), which enables a person to be active in solving environmental problems through awareness, methods, skills, and participation (Mohamed et al. 2006). The objective of the is article is to identify the importance of public awareness in environmental pollution management. Public awareness and attitude surveys allow an understanding of broader social knowledge and priorities that can contribute positively to the achievement of conservation goals. (Hawkins et al. 2016).

Additionally, in Malaysia, studies of public awareness, consciousness, and attitudes (including WTP) towards air pollution are uncommon. Thus, by understanding the public's perception of current air pollution, their environmental awareness, and attitudes towards environmental protection, this study attempts to explore this subject (Chin et al. 2019). According to Li et al. (2017), for further consideration during implementation, some constructive policy recommendations have been proposed. The reason for carrying out this study is that without public knowledge and environmental protection funding, the introduction of any initiative or legislation will not be effective (Chin et al. 2019). Therefore, the awareness surveys are crucial for some regulation and policy implementation.

The study will identify the importance of public awareness in environmental pollution management in the Paktika higher education institute. This research will answer the question: what is the level of public awareness in Paktika towards environmental protection? and what types of environmental activities are required for public awareness?

\section{MATERIALS AND METHODS}

\section{Study Area}

The latitude and longitude of Paktika province are 31.59and 33.42-degrees latitude and 67.81- and 69.54-degrees longitude, respectively. The nation has a total area of 36360 $\mathrm{km}^{2}$ with a $360 \mathrm{~km}^{2}$ boundary with Pakistan, which is 210 km from Kabul (Fig. 1).

Paktika is a third-class province according to the Afghan administrative division's political and social divisions. In

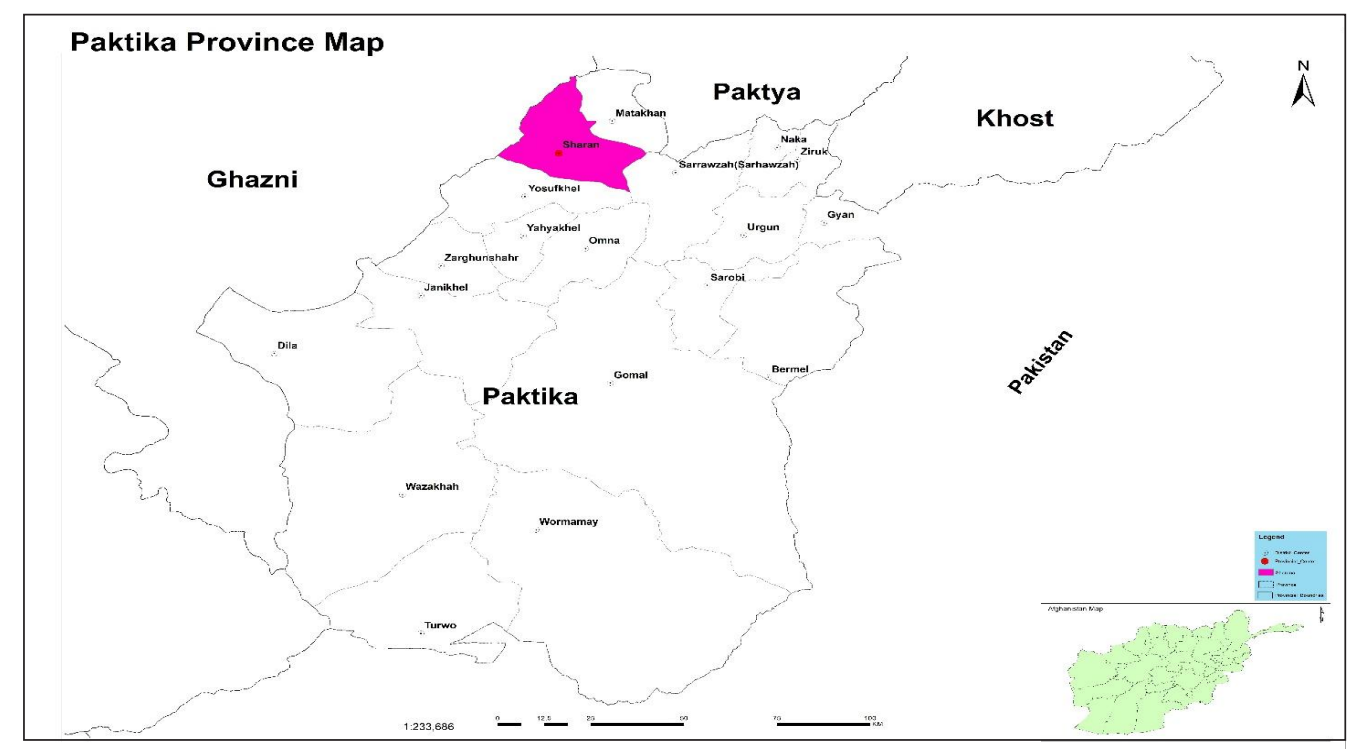

Fig. 1: Paktika Province map. 
addition to the capital, it has eight districts. It has a total population of 434742 people, with Pashtuns making up the vast majority of the population, which is divided into different tribes who speak Pashto (Mazloom Yar 2016).

\section{Paktika University}

\section{Sampling Size and Population}

The total student population of Paktika Higher Education Institute Education Faculty is 1200, and the total sample size based on Cochran's sample size formula for continuous data is:

$$
\mathrm{n}_{\mathrm{o}}=\frac{(\mathrm{t})^{2} *(\mathrm{~s})^{2}}{(\mathrm{~d})^{2}}
$$

Where $t$ is the value for each tail's chosen alpha stage (the alpha level of .05 indicates the level of risk the researcher is willing to take that true margin of error may exceed the acceptable margin of error.). Where the population's average standard deviation, and $d$ is the acceptable margin of error for the mean estimated (number of points on primary scale * acceptable margin of error). The sample size for this study with a $95 \%$ confidence level and $10 \%$ confidence interval is 71 students.

\section{Data Collection and Research Instrument}

The data is collected from primary and secondary sources. Primary data sources include field observation, and a survey instrument consisting of one set of questionnaires was con- structed and sent to target respondents to collect information that would later be used for further study to determine public awareness in environmental protection. The data collected through the questionnaires was analyzed descriptively, as well as, the data analyzed was used to support the study's desired results. The questionnaires were constructed in the Pashto National Language of Afghanistan so that the respondents could better grasp the questions and correctly answer them. Secondary data was attained from books, journals, reports, and conference proceedings. The questionnaire had closed-ended questions, and it was distributed to 71 students from the Faculty of Education. The questionnaire was reliable and consistent; therefore, every survey participant answered precisely similar questions. A comprehensive field study was conducted to collect information about the current circumstances of public awareness among the city residents. The results obtained are analyzed descriptively using SPSS 24. The research analysis method was Frequency and Percentage as it is the best and most suitable method for analyzing the question papers.

\section{RESULTS AND DISCUSSION}

The questionnaire used in this study has various components such as general information about participants, serious environmental problems of Afghanistan, solutions, public awareness tools, participation in solving environmental

\begin{tabular}{|c|c|c|c|}
\hline \multirow[t]{2}{*}{ Questions } & \multirow[t]{2}{*}{ Parameters } & \multicolumn{2}{|c|}{ Survey participants' responses } \\
\hline & & Frequency & Percentage \\
\hline \multirow[t]{5}{*}{ Respondents education level } & First-year student & 15 & 21.1 \\
\hline & Second-year student & 23 & 32.4 \\
\hline & Third-year students & 33 & 46.5 \\
\hline & Total & 71 & 100.0 \\
\hline & $\mathrm{S}$ & & \\
\hline \multirow[t]{8}{*}{ Serious environmental problems in Afghanistan } & Air pollution & 16 & 22.5 \\
\hline & Noise pollution & 6 & 8.5 \\
\hline & Water pollution & 17 & 24 \\
\hline & Soil pollution & 4 & 5.6 \\
\hline & Mismanagement of waste & 5 & 7 \\
\hline & Demolition of natural resources & 13 & 18.3 \\
\hline & Problems in the municipal system & 10 & 14.1 \\
\hline & Total & 71 & 100 \\
\hline \multirow[t]{5}{*}{ Resolutions } & Technological Improvements & 3 & 4.2 \\
\hline & Rising public awareness level & 42 & 59.2 \\
\hline & Enforcement of environmental laws & 25 & 35.2 \\
\hline & Usage of alternative materials in the industry & 1 & 1.4 \\
\hline & Total & 71 & 100 \\
\hline
\end{tabular}
problems, and others. Table 1 indicates the findings of the questionnaire. 


\begin{tabular}{|c|c|c|c|}
\hline \multirow[t]{2}{*}{ Questions } & \multirow[t]{2}{*}{ Parameters } & \multicolumn{2}{|c|}{ Survey participants' responses } \\
\hline & & Frequency & Percentage \\
\hline \multirow[t]{5}{*}{ Public awareness tools } & Conferences and seminars & 25 & 35.2 \\
\hline & Newspapers, magazines, books & 15 & 21.1 \\
\hline & Radio and $\mathrm{Tv}$ & 28 & 39.4 \\
\hline & Activities of Non-governmental organizations & 3 & 4.2 \\
\hline & Total & 71 & 100 \\
\hline \multirow[t]{5}{*}{ Following environment-related publications } & Always & 9 & 12.7 \\
\hline & Some times & 51 & 71.8 \\
\hline & Never & 7 & 9.9 \\
\hline & No answer & 4 & 5.6 \\
\hline & Total & 71 & 100 \\
\hline \multirow{5}{*}{$\begin{array}{l}\text { Types of participation in environmental ac- } \\
\text { tivities }\end{array}$} & Works as Volunteer & 49 & 69.0 \\
\hline & Financial assistance & 14 & 19.7 \\
\hline & None of them & 4 & 5.6 \\
\hline & No answer & 4 & 5.6 \\
\hline & Total & 71 & 100 \\
\hline
\end{tabular}

\section{The Current Conditions of Public Awareness on Environmental Pollution Management in Paktika}

Due to the low level of environmental awareness in Paktika, pollutants are dumped in the water, canals, and other public places (Fig. 2). If the current scenario persists, it is not unlikely that it will devolve into a catastrophe, because the government cannot prevent pollution without the participation of the people. Public awareness is critical to engaging the public in environmental protection activities.

According to the results of the study, the main reason for the government's failure to prevent pollution in Afghanistan is the lack of public awareness about environmental protection. The general public does not cooperate with the government in controlling environmental pollution. This is because they are unaware that these substances are having a detrimental effect on their health and the environment. Environmental pollution prevention cannot be achieved solely by legislation, nor can it be achieved without community participation in environmental protection. If the public is made aware of the effects of environmental problems such as climate change, diversity, ozone depletion, endangered species, illegal trade, environmental pollution, and wastewater, the government will be able to prevent such problems very easily.

People cannot make effective decisions without public knowledge, comprehension of available science and technical evidence, and support for government regulations and acts. Coping skills can be enhanced, health risks can be minimized, and lives can be saved by increasing public knowledge, collaboration, and dedication. It is important in public health practice to keep the public aware of any danger or hazard that can impact their health and well-being (Rapaport \& Ashkenazi 2016). Because the majority of pollutants are produced by individuals, the government alone will not be able to avoid them if they do not help clean up. Therefore, the general public should be involved in environmental protection activities, for which public awareness is very important. Public awareness in the field of environmental protection is very important because only through public awareness and access to information, we can involve the general public in environmental protection activities (Rahmani \& Nor Anuar 2019). Rather than asking people to come to you, a good public awareness campaign entails taking the message to them. This necessitates diverse mediums to reach out to various segments of the population, including mass media, magazines (brochures, posters), meetings and hearings, publicity merchandise, social events, role-playing and community theater, and the Internet (Minkova 2002). A broad range of strategies and techniques for improving communication and public awareness are available, and they can be used to engage the public in environmental protection activities. Examples Modern mass media such as newspapers, magazines, radio, television, and film are examples of modern mass media; conventional media such as national broadband radio; printed materials such as posters, leaflets, and illustrated booklets, billboards, wall-writing, messages printed on bags, transport, signs, and other things used or encountered in daily life; use of popular personalities as advocates; school programs; outdoor education programs; and interpretive facilities in protected areas (Solongp 2012).

\section{CONCLUSION}

Currently, air pollution, water pollution, destruction of natural resources, and mismanagement of waste are severe environmental problems in Afghanistan. This is because they are oblivious to the fact that the waste products, they generate have a negative impact on their health and the environment. If this situation persists, it is not unlikely that 

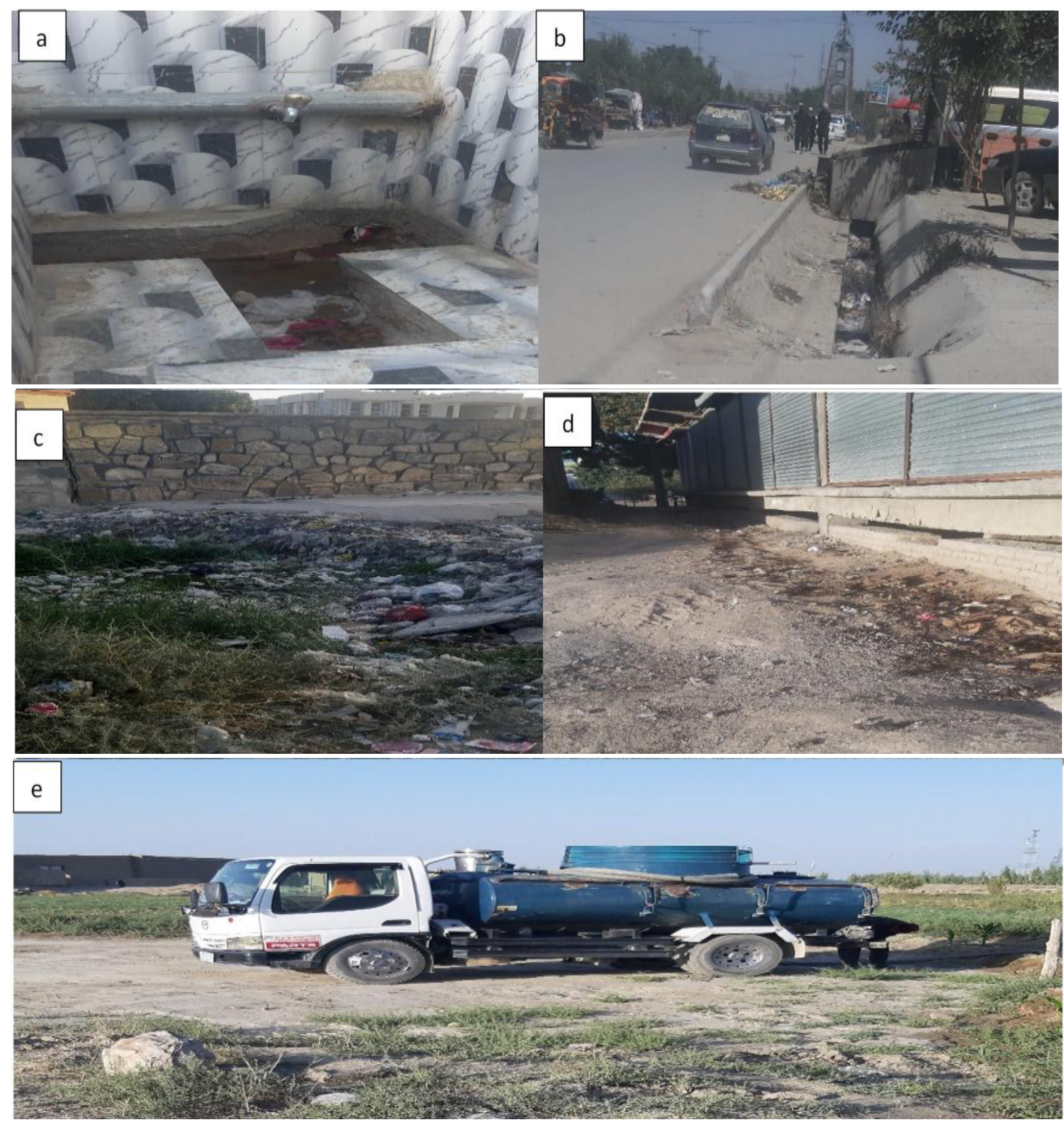

Fig. 2: a- Sewage at the toilet of the mosque, b- waste materials on the main road, c- waste materials and wastewater next to the Public Health Department and Central Hospital, d- sewage in front of shops, e- emptying wastewater tankers in areas close to homes.

it will devolve into a disaster, as the government cannot prevent pollution on its own. Public awareness plays a very important and fundamental role in environmental pollutions management. This is because, through public awareness and access to information, we can encourage the general public to participate in natural resource conservation and environmental protection activities. A wide variety of tools are available such as mass media, traditional media, wall-writing, school programs, and outdoor education pro- grams for promoting communication and public awareness. Consequently, it is recommended that various environmental activities are required for public awareness to protect the environment.

\section{REFERENCES}

Apichatibutarapong, S. 2018. Factors affecting public awareness concerning the university environment. In: Multidisciplinary Digital Publishing Institute Proceedings, 2(22): 1369. 
Chin, Y.S.J., De Pretto, L., Thuppil, V. and Ashfold, M.J. 2019. Public awareness and support for environmental protection: A focus on air pollution in peninsular Malaysia. PloS One, 14(3): e0212206.

Cochran, W.G. 1977. Sampling techniques. 3rd edition. John Wiley \& Sons, New York.

Curdt-Christiansen, X.L. 2020. Environmental literacy: Raising awareness through Chinese primary education textbooks. Lang. Cult. Curric., 1: $1-16$.

Debrah, J.K., Vidal, D.G. and Dinis, M.A. 2021. Raising awareness on solid waste management through formal education for sustainability: A developing countries evidence review. Recycling, 6: 106

Ekmekçi, M. and Günay, G. 1997. Role of public awareness in groundwater protection. Environ. Geol., 30(1-2): 81-87.

Hawkins, J.P., O’Leary, B.C., Bassett, N., Peters, H., Rakowski, S., Reeve, G. and Roberts, C.M. 2016. Public awareness and attitudes towards marine protection in the United Kingdom. Marine Pollut. Bull., 111(12): 231-236.

Li, Q., Liu, G., Leamon, G., Liu, L.C.C., Cai, B. and Chen, Z.A.A. 2017. A national survey of public awareness of the environmental impact and management of CCUS technology in China. Energy Proc., 114(November 2016): 7237-7244.

Nazarenko, A.V. and Kolesnik, A.I. 2018. Raising environmental awareness of future teachers. Int. J. Instr., 11(3): 63-76.

Minkova, Y. 2002. Developing Skills of NGOs: Public Education to Raise Environmental Awareness. Ady Endre ut 9-11, 2000, The Regional Environmental Center for Central and Eastern Europe, Szentendre, Hungary,

Mohamed, E., Kidundo, M. and Tagelseed, M. 2006. Environmental education_and public awareness. Workshop on Post Conflict National Plan for Environmental Management in Sudan, Khartoum, Sudan, p. 3.
Mazloom Yar, F.G. 2016. Political Geography of Afghanistan, Islah Afkar Publishing Society, Jalalabad.

Mukhtar, S., Wafa, W., Halimzai, H. and Shams, A.K. 2016. Planning for the solid waste management of the central park in new capital development of Afghanistan. J. Environ. Protect., 7(06): 805.

Rahmani, H. and Nor Anuar, A. 2019. Challenges and resolutions for sustainable domestic wastewater management in Kabul City, Afghanistan. Int. J. Eng. Adv. Technol., 12: 1398.

Rapaport, C. and Ashkenazi, I. 2016. Incorporating public awareness into climate change health planning. SM Trop. Med. J., 1: 1-13.

Sola, A. 2014. Environmental education and public awareness. J. Educ. Social Res., 4(3): 332.

Solongo, T. 2012. UNDP-GEF Project: Integrated Natural Resource Management in the Baikal Basin Transboundary Ecosystem. UNOPS and UNDP.

UNEP 2006. Raising awareness of climate change: A handbook for government focal points. United Nations Environment Programme's Division of Environmental Law and Conventions, CH-1219 Châtelaine (Geneva), Switzerland.

UNESCO, U. 1978. Recommendations of the Intergovernmental Conference on Environmental Education Tbilisi. USSR. France: UNESCO, pp.1-96.

Wafa, W., Hairan, M.H. and Waizy, H. 2020. The impacts of urbanization on Kabul City's groundwater quality. Int. J. Adv. Sci. Technol., 29(4): 10796-10809.

Xua, L., Shen, J., Marinova, D. and Guo, X. 2011. Quantitative Assessment on Public Awareness of Environmental Protection in Response to Environmental Incidents: A Case for Taihu Lake Algae Bloom. 19th International Congress on Modelling and Simulation, 2011, 12-16 December, Perth Convention and Exhibition Centre in Perth, Western Australia, MODSIM, p. 1718. 